\title{
Mitochondrial Permeability Transition in the Switch From Necrotic to Apoptotic Cell Death in Ischemic Rat Hepatocytes
}

\author{
JAE-SUNG KIM, TING QIAN, and JOHN J. LEMASTERS \\ Department of Cell and Developmental Biology, School of Medicine, University of North Carolina, Chapel Hill, North Carolina
}

Background \& Aims: Ischemia/reperfusion can initiate both necrotic and apoptotic death of hepatocytes. Previous work showed that onset of the mitochondrial permeability transition (MPT) can initiate necrotic cell death after reperfusion, but the MPT is also implicated in apoptosis. Here, we investigated factors regulating how cell death switches from necrosis to apoptosis after ischemia/reperfusion injury. Methods: Overnight cultured rat hepatocytes were incubated in anoxia at $\mathrm{pH}$ 6.2 for 4 hours and reoxygenated at $\mathrm{pH} 7.4$ to simulate ischemia/reperfusion. Some cells were incubated with fructose plus glycine just before and then continuously after reperfusion. Development of apoptosis was evaluated by examining chromatin condensation, nuclear DNA fragmentation, and caspase 3 activity. Results: Reperfusion with the glycolytic substrate fructose plus the cytoprotective amino acid glycine prevented necrotic cell killing. Instead, apoptosis developed within 12 hours as shown by nuclear chromatin changes, TUNEL staining, and caspase 3 activation. This apoptotic cell killing was prevented by cyclosporin A, an MPT blocker, and by pancaspase and caspase 3 inhibition, but not by caspase 8 inhibition. Cyclosporin A also blocked caspase-3 activation. Reperfusion with glycine alone prevented necrotic cell death but did not induce apoptosis and only poorly promoted recovery of ATP, whereas fructose alone during reperfusion promoted both ATP recovery and apoptosis. Conclusions: Glycolytic ATP generation after reperfusion prevents necrotic killing of hepatocytes after simulated ischemia/reperfusion despite onset of the MPT. Instead, the MPT promotes caspase-and ATP-dependent apoptosis. Thus, the MPT is a common mechanism responsible for both necrosis and apoptosis after ischemia/reperfusion.

C ells and tissues subjected to hypoxia and ischemia develop acidosis, which protects against hypoxic cell killing. However, restoration of normal $\mathrm{pH}$ during reoxygenation is an important factor precipitating rapid necrotic cell death. ${ }^{1-5}$ Previous work showed that the cyclosporin A-sensitive mitochondrial permeability transition (MPT) is a key event leading to a $\mathrm{pH}$-dependent necrotic cell death in hepatocytes after ischemia/reperfusion. ${ }^{5}$ Opening of high conductance permeability tran- sition (PT) pores in mitochondria initiates the MPT. As a consequence of the MPT, mitochondria uncouple, depolarize, and undergo large amplitude swelling. Outer membrane rupture after swelling allows release of cytochrome $\mathrm{c}$ and other proapoptotic factors into the cytosol from the intermembrane space. Acidotic $\mathrm{pH}(<7)$ inhibits $\mathrm{PT}$ pore opening, and the rise of intracellular $\mathrm{pH}$ after reperfusion appears to be a critical event initiating reperfusion-induced onset of the MPT. Cyclosporin A (CsA) blocks opening of PT pores and protects hepatocytes and other cells against necrotic cell death after ischemia/ reperfusion. ${ }^{5,6}$

Apoptosis or programmed cell death is widely considered as a distinct entity from necrotic cell death, also called oncosis. ${ }^{7}$ Apoptosis is essential for regulation of tissue mass and immune surveillance. ${ }^{8}$ As such, apoptosis is tightly regulated by a variety of extracellular and intracellular signals. ${ }^{9}, 10$ Signaling pathways contributing to apoptosis are often driven by the sequential activation of caspases, mediated in part by mitochondrial depolarization and cytochrome c release. Despite the presumed fundamental difference between apoptosis and necrosis, growing evidence supports an essential role of the MPT in the release of cytochrome $\mathrm{c}$ and initiation of apoptosis in many models, including hepatocytes exposed to tumor necrosis factor $\alpha$ (TNF- $\alpha)$ and Fas ligation. ${ }^{11,12}$ Moreover, although ischemia/reperfusion is usually associated with necrotic cell death, ${ }^{5,13}$ more recent studies have shown that apoptosis also occurs after ischemia/reperfusion in cells from liver and other organs. ${ }^{14-16}$

Accordingly, the goal of the present study was to determine the role of MPT in the development of apo-

Abbreviations used in this paper: Ac-DEVD-AFC, N-acetyl-Asp-Glu-ValAsp-7-amino-4-trifluoromethyl coumarin; ATP, adenosine 5'-triphosphate; dATP, 2'-deoxyadenosine 5'-triphosphate; CsA, cyclosporin A; HDM, hormonally defined medium; KRH, Krebs-Ringer-HEPES; LDH, lactate dehydrogenase; MPT, mitochondrial permeability transition; PT pore, permeability transition pore; TNF- $\alpha$, tumor necrosis factor $\alpha$; TUNEL, terminal deoxynucleotidyl transferase-mediated dUTP nick end labeling.

(C) $\mathbf{2 0 0 3}$ by the American Gastroenterological Association 0016-5085/03/\$35.00 doi:10.1053/gast.2003.50059 
ptosis after ischemia/reperfusion to cultured rat hepatocytes and to characterize the signaling factors that lead either to necrotic or apoptotic death. Our results indicate the availability of glycolytic adenosine 5'-triphosphate (ATP) after reperfusion switches cell killing from MPTdependent necrotic cell death to MPT- and caspasedependent apoptosis. Thus, a common mechanism, MPT, is responsible for both apoptosis and necrosis after ischemia/reperfusion injury.

\section{Materials and Methods}

\section{Hepatocyte Isolation and Culture}

The animal study protocol was approved by the Institutional Animal Care and Use Committee of the University of North Carolina at Chapel Hill. Hepatocytes were isolated from 1-day-fasted male Sprague-Dawley rats $(250-300 \mathrm{~g})$ by collagenase perfusion, as previously described, ${ }^{5}$ and resuspended in Waymouth's medium MB-752/1 containing 100 units $/ \mathrm{mL}$ penicillin, $100 \mu \mathrm{g} / \mathrm{mL}$ streptomycin, $10 \%$ fetal calf serum, $100 \mathrm{nmol} / \mathrm{L}$ insulin, and $100 \mathrm{nmol} / \mathrm{L}$ dexamethasone. Cell viability was greater than $90 \%$, as determined by trypan blue exclusion. For cell viability assays, aliquots $(1 \mathrm{~mL})$ of $1.5 \times$ $10^{5}$ cells were plated onto 24-well microtiter plates (Falcon, Lincoln Park, NJ). For microscopic studies, $4.5 \times 10^{5}$ cells were cultured on $40-\mathrm{mm}$ round glass coverslips in $60-\mathrm{mm}$ culture dishes. For caspase 3 assays, hepatocytes were plated on coverslips at a concentration of $6 \times 10^{6}$ cells. All plates and coverslips were coated with $0.1 \%$ type 1 rat-tail collagen. Hepatocytes were used after overnight culture in humidified $5 \% \mathrm{CO}_{2}, 95 \%$ air at $37^{\circ} \mathrm{C}$.

\section{Simulation of Ischemia/Reperfusion in Cultured Rat Hepatocytes}

To simulate the anoxia, substrate deprivation, and tissue acidosis of ischemia, hepatocytes were incubated in KrebsRinger-N-2 hydroxyethylpiperazine-N-2 ethanesulfonic acid (HEPES) buffer (KRH) containing (in mmol/L) $115 \mathrm{NaCl}, 5$ $\mathrm{KCl}, 2 \mathrm{CaCl}_{2}, 1 \mathrm{KH}_{2} \mathrm{PO}_{4}, 1.2 \mathrm{MgSO}_{4}$, and 25 HEPES at $\mathrm{pH}$ 6.2 in an anaerobic chamber (Coy Laboratory Products, Ann Arbor, MI) for 4 hours. Reperfusion was simulated by replacing anaerobic $\mathrm{KRH}$ at $\mathrm{pH} 6.2$ with aerobic hormonally defined medium (HDM) containing $0.1 \mu \mathrm{mol} / \mathrm{L}$ insulin, $2 \mathrm{mmol} / \mathrm{L}$ L-glutamate, $5 \mu \mathrm{g} / \mathrm{mL}$ transferrin, $3 \mu \mathrm{mol} / \mathrm{L}$ selenium, and 10 $\mathrm{nmol} / \mathrm{L}$ free fatty acids in RPMI 1640 medium at $\mathrm{pH} 7.4$. This model is widely used to study mechanisms of ischemia/reperfusion injury in cells cultured from liver and other tissues. ${ }^{1,5,17}$ Anoxia in the anaerobic chamber was maintained under an atmosphere of $90 \% \mathrm{~N}_{2}-10 \% \mathrm{H}_{2}$. Oxygen tension in the chamber was monitored by a gas analyzer (Model 10; Coy Laboratory Products) and was less than 0.001 torr. In some experiments, hepatocytes were treated with $20 \mathrm{mmol} / \mathrm{L}$ fructose and $5 \mathrm{mmol} / \mathrm{L}$ glycine at 20 minutes before and continuously after reperfusion.

\section{Cell Viability Assay}

Cell viability was determined by propidium iodide fluorometry using a multiwell fluorescence reader (BMG Lab Technologies, Offenburg, Germany), as previously described. ${ }^{18}$ Briefly, hepatocytes were incubated in HDM containing $30 \mu \mathrm{mol} / \mathrm{L}$ propidium iodide. Fluorescence from each well was measured at excitation and emission wavelengths of $530 \mathrm{~nm}$ and $590 \mathrm{~nm}$, respectively. For each well, fluorescence (A) at 20 minutes after addition of propidium iodide was measured before exposure to anoxia and then at given times thereafter (X). Experiments were terminated by plasma membrane permeabilization with $375 \mu \mathrm{mol} / \mathrm{L}$ digitonin to label all cells with propidium iodide. After 20 minutes, a final fluorescence measurement (B) was made. The percentage of viable cells $(\mathrm{V})$ was calculated as $\mathrm{V}=100(\mathrm{~B}-\mathrm{X}) /(\mathrm{B}-\mathrm{A})$. Propidium iodide fluorescence increases as the plasma membrane permeability barrier fails in individual cells at onset of necrotic cell death. ${ }^{19}$ Cell viability assessed by propidium iodide fluorometry correlates closely with trypan blue exclusion and enzyme release. ${ }^{20}$

\section{Lactate Dehydrogenase}

Lactate dehydrogenase ( $\mathrm{LDH}$ ) activity in the incubation medium was measured spectrophotometrically from $\mathrm{NAD}^{+}$reduction to $\mathrm{NADH}$ in the presence of pyruvate, as described. ${ }^{18}$ Total activity of $\mathrm{LDH}$ was determined after permeabilizing cells with $375 \mu \mathrm{mol} / \mathrm{L}$ digitonin. $\mathrm{LDH}$ release in the incubation medium was expressed as the percentage of total LDH activity.

\section{Nuclear Morphology of Hepatocytes}

To detect development of necrosis and apoptosis, hepatocytes were fixed at $4^{\circ} \mathrm{C}$ for 1 hour with $1 \%$ paraformaldehyde containing $80 \mathrm{mmol} / \mathrm{L} \mathrm{Na}_{2} \mathrm{HPO}_{4}$ and $20 \mathrm{mmol} / \mathrm{L} \mathrm{NaH} \mathrm{PO}_{4}$. Fixation under these conditions did not permeabilize plasma membranes. Cells were washed twice with cold, fresh $\mathrm{KRH}$ and then incubated with cold $\mathrm{KRH}$ containing $10 \mu \mathrm{mol} / \mathrm{L}$ propidium iodide for 20 minutes. Subsequently, the hepatocytes were placed on the stage of a fluorescence microscope (Zeiss, Germany). Red nuclear fluorescence was imaged with a Leica $50 \times($ N.A. $=1.00)$ water immersion objective lens to visualize nonviable cells stained with propidium iodide. After collecting images, cells were treated with $375 \mu \mathrm{mol} / \mathrm{L}$ digitonin to permeabilize plasma membranes of all cells. Propidium iodide staining in nuclei was then compared before and after digitonin treatment. Chromatin condensation and nuclear fragmentation in stained nuclei indicated development of apoptosis. $^{21}$

\section{TUNEL Assay}

Cleavage of nuclear DNA into oligonucleosome fragments is a key event in apoptosis. To identify nuclear DNA fragmentation, the terminal deoxynucleotidyl transferase (TdT)-mediated dUTP nick-end labeling (TUNEL) assay was performed by labeling free 3-hydroxyl ends with fluorescein- 
dUTP using a commercial kit according to the manufacturer's instructions (TUNEL Assay Kit; Roche Molecular Biochemicals, Indianapolis, IN). Green nuclear fluorescence staining was observed with a fluorescence microscope. Five random fields were counted for each TUNEL-stained coverslip. In addition, the number of nuclei in each field was independently counted using bright field illumination. The percentage of TUNEL staining was expressed as the number of positively stained nuclei divided by the total number of nuclei.

\section{Caspase 3 Activity}

Caspase 3 activity was determined by measuring cleavage of the specific caspase 3 substrate $\mathrm{N}$-acetyl-Asp-GluVal-Asp-7-amino-4-trifluoromethyl coumarin (Ac-DEVDAFC) using a commercial kit (Caspase 3 Activity Assay; Roche Molecular Biochemicals, Indianapolis, IN). Briefly, hepatocytes were plated on coverslips at a concentration of $6 \times$ $10^{6}$ cells and cultured overnight. After exposure to 4 hours of simulated ischemia, cells were reperfused for 0,3 , or 8 hours in the presence of $20 \mathrm{mmol} / \mathrm{L}$ fructose and $5 \mathrm{mmol} / \mathrm{L}$ glycine. Cells were carefully scraped from coverslips and stored in a lysis buffer at $4^{\circ} \mathrm{C}$ for 1 hour. Cell lysis and the immunosorbent fluorescence enzyme assay were performed by following the manufacturer's protocol.

\section{ATP Measurement}

Cellular levels of ATP in cultured rat hepatocytes were determined with a luciferin-luciferase kit (Promega Enliten, Madison, WI) using luminometer, as described previously. ${ }^{5}$

\section{Statistics}

Differences between means were compared by the Student $t$ test using a level of significance of $P<0.05$. Data were expressed as means $\pm \mathrm{SE}$. All experiments are representative of at least 3 different cell isolations.

\section{Results}

\section{Protection by Fructose and Glycine Against Necrotic Cell Death After Simulated Ischemia/Reperfusion to Cultured Rat Hepatocytes}

To simulate the anoxia, substrate deprivation, and acidosis of hepatic ischemia, overnight cultured hepatocytes were placed in sealed, 24-well microtiter plates in an anaerobic chamber and exposed to preequilibrated anaerobic Krebs-Ringer-HEPES (KRH) buffer at pH 6.2 and $37^{\circ} \mathrm{C}$. After exposure of hepatocytes to simulated ischemia for 4 hours, reperfusion was simulated by replacing anaerobic $\mathrm{KRH}$ at $\mathrm{pH} 6.2$ with aerobic hormonally defined RPMI 1640 medium (HDM) at $\mathrm{pH}$ 7.4. After reoxygenation, necrotic cell killing assessed by propidium iodide fluorometry increased to more than $60 \%$ within 2 hours (Figure 1). By contrast, when hepa-

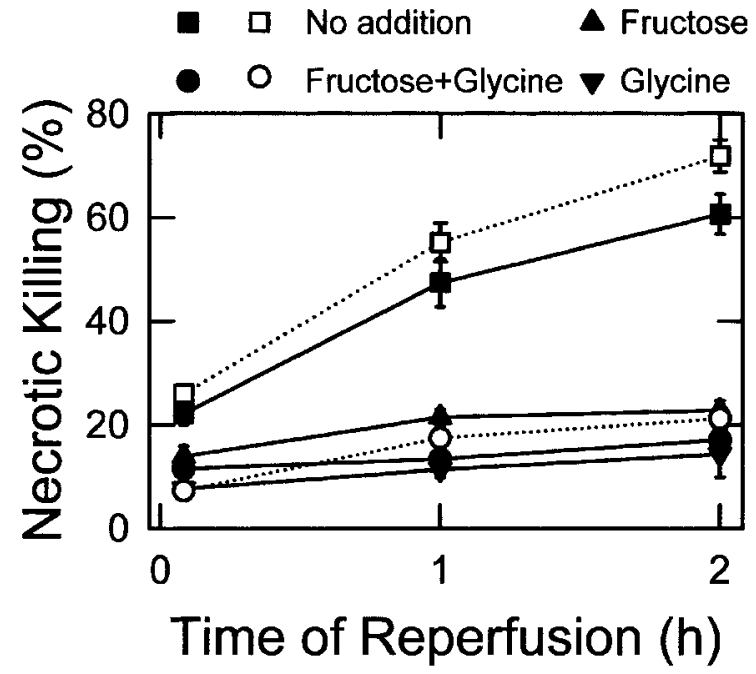

Figure 1. Protection by fructose and glycine against reperfusion in jury. Hepatocytes were incubated in anaerobic KRH buffer at $\mathrm{pH} 6.2$ for 4 hours to simulate ischemia and then reoxygenated in $\mathrm{HDM}$ at $\mathrm{pH}$ 7.4 to simulate reperfusion, as described in Materials and Methods section. Some cells were treated with $20 \mathrm{mmol} / \mathrm{L}$ fructose and/or 5 $\mathrm{mmol} / \mathrm{L}$ glycine beginning at 20 minutes before and continuously after reperfusion. Cell viability was measured by propidium iodide fluorometry (solid symbols) and LDH release (open symbols and dotted lines). Values are means \pm SE from 3 and more hepatocyte isolations.

tocytes were treated with $20 \mathrm{mmol} / \mathrm{L}$ fructose (a glycolytic substrate) and $5 \mathrm{mmol} / \mathrm{L}$ glycine (a membrane stabilizing amino acid) together, beginning 20 minutes before and then continuously after reperfusion, little cell killing occurred after reperfusion (Figure 1). Cell viability was also well maintained when hepatocytes were treated with fructose or glycine alone just before reperfusion. These results in which hepatocytes were reperfused with hormonally defined RPMI 1640 medium confirmed our previous findings in which glycine blocked killing of hepatocytes reperfused with simple aerobic KRH buffer at $\mathrm{pH} 7.4$ instead of HDM. ${ }^{5}$ In addition, we measured $\mathrm{LDH}$ release as an independent measure of necrotic cell death in these experiments. Reperfusion-induced cell killing estimated by LDH release was very similar to cell killing estimated by propidium iodide uptake and was prevented when the hepatocytes were reperfused in the presence of fructose plus glycine (Figure 1, compare open and closed symbols).

\section{Apoptotic Changes After Ischemia/Reperfusion in the Presence of Fructose Plus Glycine}

Ischemia/reperfusion can lead to both necrotic cell death and apoptosis in liver and other tissues. $5,7,8,13-16,22-25$ To determine the effects of fructose and glycine on apoptosis after ischemia/reperfusion, we examined the morphology of 

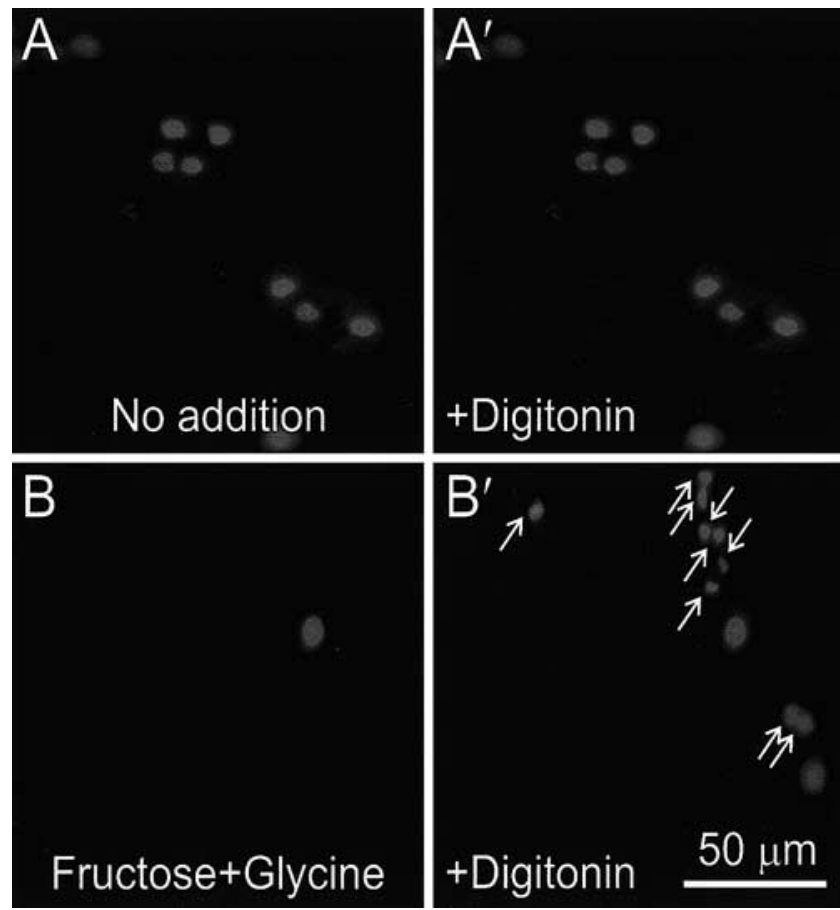

Figure 2. Protection against necrotic cell death and onset of apoptosis after reperfusion with fructose plus glycine. Hepatocytes were subjected to simulated ischemia/reperfusion, as described in Figure 1. After 4 hours of anoxia, hepatocytes were reoxygenated with HDM for 8 hours in the presence $\left(B\right.$ and $\left.B^{\prime}\right)$ or absence $\left(A\right.$ and $\left.A^{\prime}\right)$ of 20 $\mathrm{mmol} / \mathrm{L}$ fructose plus $5 \mathrm{mmol} / \mathrm{L}$ glycine. Cells were fixed and incubated with $10 \mu \mathrm{mol} / \mathrm{L}$ propidium iodide. Red nuclear fluorescence was imaged before $(A$ and $B)$ and after $\left(A^{\prime}\right.$ and $\left.B^{\prime}\right)$ treatment with 375 $\mu \mathrm{mol} / \mathrm{L}$ digitonin. In the absence of fructose plus glycine, all nuclei were stained with propidium iodide before digitonin permeabilization, indicating necrotic cell death $(A)$. In the presence of fructose plus glycine $(F+G)$, most nuclei were unlabeled before digitonin $(B)$. After digitonin, nuclei showing fragmentation and chromatin condensation became evident, indicating development of apoptotic cell death ( $B^{\prime}$, arrows).

nuclei. After 4 hours of anoxia, hepatocytes were reperfused for 8 hours with HDM in the presence and absence of fructose plus glycine. The cells were fixed and exposed to 10 $\mu \mathrm{mol} / \mathrm{L}$ propidium iodide before and after plasma membrane permeabilization with $375 \mu \mathrm{mol} / \mathrm{L}$ digitonin. In the absence of fructose plus glycine, virtually all cell nuclei labeled with propidium iodide prior to addition of digitonin because subsequent addition of digitonin did not increase the number of propidium iodide-stained nuclei (Figure $2 A$ and $A^{\prime}$ ). These findings indicated that onset of necrotic cell death had occurred in virtually all cells. In contrast, when hepatocytes were reperfused in the presence of fructose plus glycine together, very few nuclei stained with propidium iodide in unpermeabilized cells (Figure $2 B$ and $B^{\prime}$ ). Measurements of $\mathrm{LDH}$ release also showed that fructose and glycine prevented most necrotic cell killing after 8 hours of reperfusion (data not shown). These observations confirmed that fructose plus glycine protected against necrotic cell killing after reperfusion. Under these conditions, however, most reperfused hepatocytes showed chromatin condensation and nuclear fragmentation (Figure $\left.2 B^{\prime}\right)$, characteristics of apoptosis. This result indicated that when fructose plus glycine prevented necrotic cell death, apoptosis developed instead after ischemia/reperfusion.

\section{Inhibition of TUNEL Staining by Cyclosporin A and Caspase Inhibitors After Ischemia/ Reperfusion}

To confirm that nuclear changes after reperfusion represented apoptosis, TUNEL staining was performed. After 12 hours of reperfusion in the presence of fructose plus glycine, nearly $60 \%$ of hepatocytes were TUNEL positive (Figure $3 A$, panel a, and $B$ ). Cyclosporin A (CsA) is a specific blocker of the mitochondrial permeability transition. ${ }^{26,27}$ When hepatocytes were treated with CsA during the last 20 minutes of ischemia and then during reperfusion, TUNEL staining was nearly prevented (Figure $3 A$, panel $\mathrm{b}$, and $B$ ). Cs $A$ is an immunosuppressive agent that also inhibits calcineurin. ${ }^{28}$ Thus, suppression of TUNEL staining by CsA might be a consequence of calcineurin inhibition. To test this possibility, hepatocytes were treated with $1 \mu \mathrm{mol} / \mathrm{L}$ tacrolimus, an immunosuppressive agent that inhibits calcineurin but does not block the MPT. ${ }^{29}$ However, tacrolimus did not prevent reperfusion-induced TUNEL staining (Figure $3 A$, panel c, and $B$ ). Taken together, these results support the conclusion that the CsA-dependent opening of PT pores mediates onset of apoptosis after ischemia/reperfusion to hepatocytes.

Caspases are key components of apoptotic signaling. In TNF- $\alpha$ - and Fas-dependent apoptosis in hepatocytes, the MPT is downstream of caspase 8 activation and upstream of activation of caspase 3. ${ }^{11,12}$ To implicate roles for caspases in ischemia/reperfusion-induced apoptosis, hepatocytes were treated with N-benzyloxycarbonyl-Val-Ala-Asp-fluoromethyl ketone (zVAD; a pancaspase inhibitor), N-acetyl-Asp-Glu-Val-Asp-CHO (DEVD; a caspase 3 inhibitor), or N-acetyl-Ile-Glu-ThrAsp-fluoromethyl ketone (IETD; a caspase 8 inhibitor) for 20 minutes before and then following reperfusion with fructose plus glycine together. zVAD and DEVD blocked TUNEL staining in reperfused cells, but IETD did not (Figure $3 A$ ). The extent of the inhibition of apoptosis by zVAD and DEVD was similar to that by CsA (Figure 3B). These results implicated that activation of caspase 3, but not caspase 8, was essential for the development of apoptosis after ischemia/reperfusion to hepatocytes. 


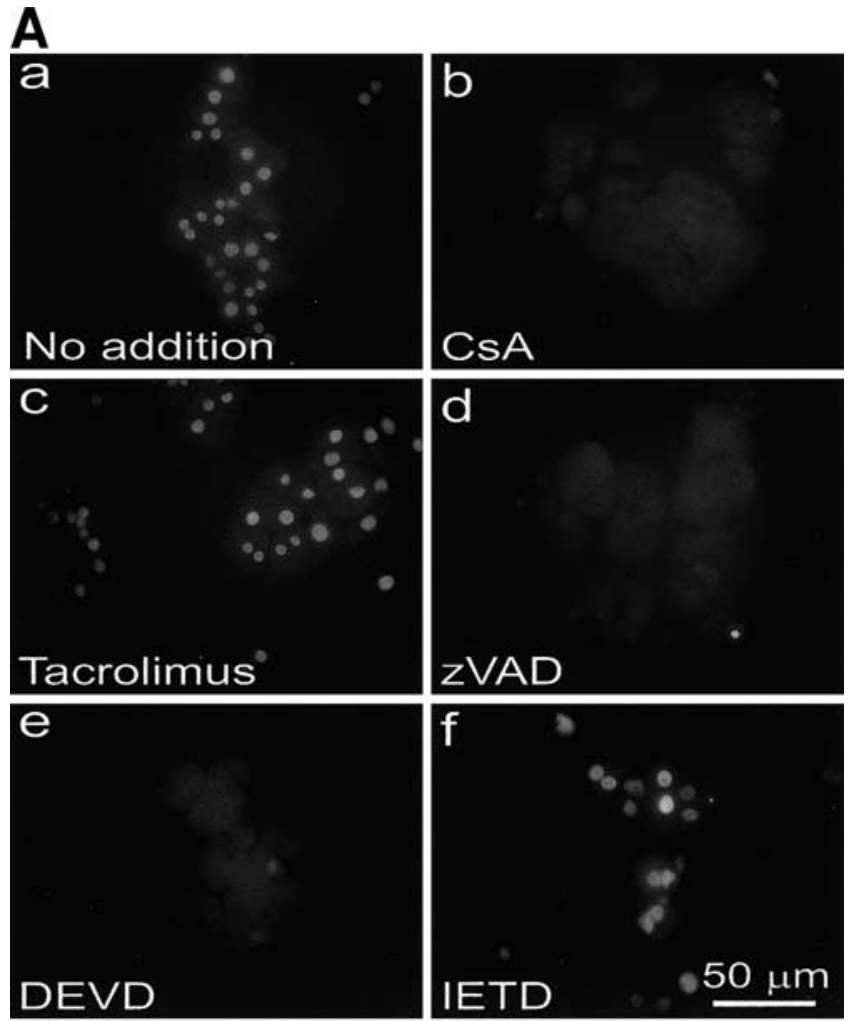

B

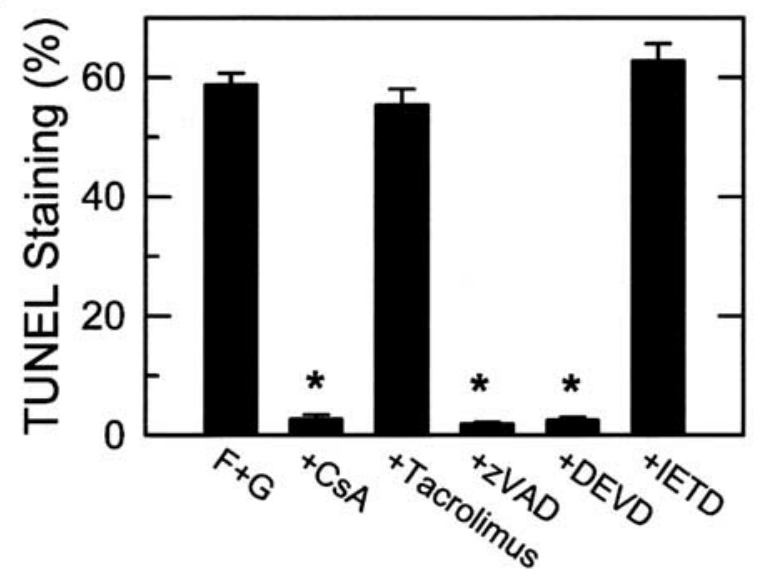

Figure 3. TUNEL staining for apoptosis after reperfusion: Protection by cyclosporin A and caspase 3 inhibitors. Hepatocytes were incubated in anoxic $\mathrm{KRH}$ at $\mathrm{pH} 6.2$ for 4 hours and reoxygenated in fructose plus glycine $(\mathrm{F}+\mathrm{G})$-containing $\mathrm{HDM}$ at $\mathrm{pH} 7.4$, as described in Figure $2 B$. Hepatocytes were treated with no addition, $1 \mu \mathrm{mol} / \mathrm{L}$ CsA, $1 \mu \mathrm{mol} / \mathrm{L}$ tacrolimus, $50 \mu \mathrm{mol} / \mathrm{L}$ zVAD, $50 \mu \mathrm{mol} / \mathrm{L}$ DEVD, or 50 $\mu \mathrm{mol} / \mathrm{L}$ IETD beginning at 20 minutes before and then continuously after reperfusion. After 12 hours, TUNEL staining was performed as described in Materials and Methods section. In $A$, note prominent TUNEL staining after reperfusion (a), which was blocked by CsA (MPT blocker; b), zVAD (pancaspase inhibitor; d), and DEVD (caspase 3 inhibitors; e) but not by tacrolimus (non-MPT-blocking immunosuppressant; c) and IETD (caspase 8 inhibitor; f). In $B$, the percentage of TUNEL labeling was expressed as the number of TUNEL-positive nuclei divided by the total number of nuclei. Results are means $\pm \mathrm{SE}$ from 3 hepatocyte isolations. $* P<0.05$ vs. $\mathrm{F}+\mathrm{G}$.

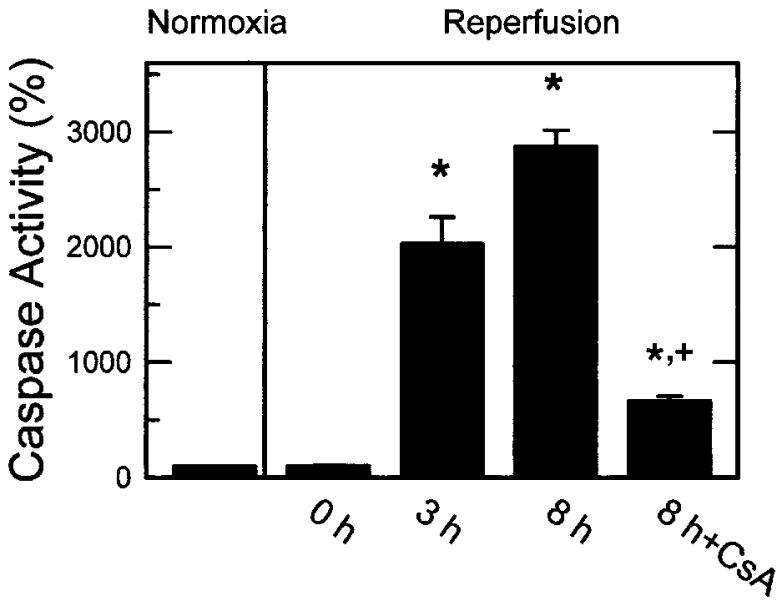

Figure 4. Activation of caspase 3 after ischemia/reperfusion. Hepatocytes in $60-\mathrm{mm}$ culture dishes were subjected to 4 hours of ischemia and 0,3 , or 8 hours of reperfusion in the presence of fructose plus glycine, as described in Materials and Methods section. Some hepatocytes were reperfused for 8 hours in the presence of 8.3 $\mathrm{nmol} / 10^{6}$ cells $\mathrm{CsA}$, beginning at 20 minutes before reperfusion and then continuously after reperfusion. In comparison with normoxic hepatocytes incubated for 8 hours in HDM, caspase 3 activity was determined using a commercial kit. Caspase 3 activity was expressed as the percentage of the normoxic activity. Results are means $\pm \mathrm{SE}$ from 3 hepatocyte isolations. ${ }^{*} P<0.05$ vs. normoxia, ${ }^{+} P<0.05$ vs. 3 hours and 8 hours.

\section{Reperfusion of Hepatocytes in the Presence of Fructose and Glycine Increases Caspase 3 Enzyme Activity}

The effect of simulated ischemia/reperfusion on caspase 3 activity was evaluated using a fluorometric assay. After 4 hours ischemia, hepatocytes were reperfused for 0,3 , and 8 hours in the presence of fructose plus glycine together. Some hepatocytes were also incubated in aerobic reperfusion medium for 8 hours at $\mathrm{pH} 7.4$ but without prior exposure to ischemia (normoxia). Caspase activity did not change at the end of ischemia (zero hours of reperfusion), but, after 3 and 8 hours of reperfusion, hepatocytes showed a 20- and 28-fold increase, respectively, in caspase 3 activity compared with normoxic cells (Figure 4). Reperfusion in the presence of CsA substantially blocked this caspase 3 activation (Figure 4).

\section{Glycolytic Energy Supply Permits Development of Apoptosis After Ischemia/Reperfusion}

Execution of caspase-dependent apoptosis requires ATP (or dATP), ${ }^{30}$ whereas necrosis is the consequence of ATP depletion. ${ }^{31,32}$ Thus, the presence or absence of cellular ATP can operate as a switch, directing cells either to apoptosis or necrosis. ${ }^{33-35}$ In hepatocytes, glycolysis of fructose increases cellular ATP content when mitochondrial oxidative phosphorylation is 


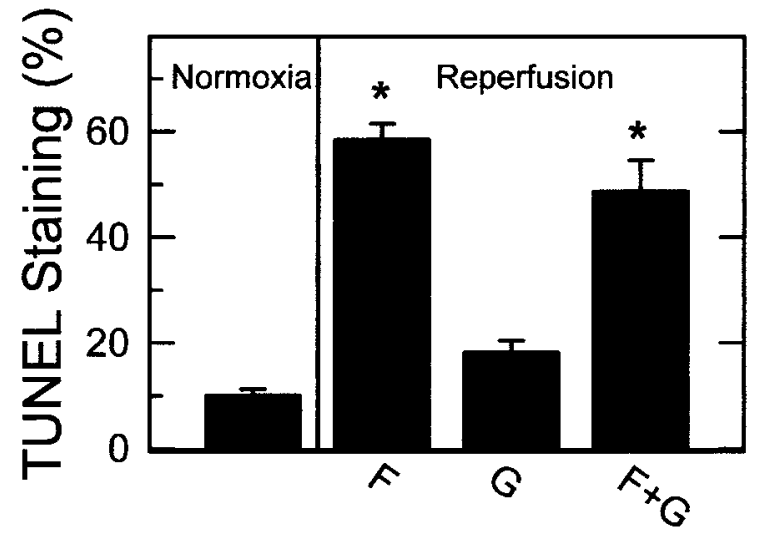

Figure 5. Development of apoptosis by fructose but not by glycine after ischemia/reperfusion. After 4 hours of anoxia at $\mathrm{pH} 6.2$, hepatocytes were treated with $20 \mathrm{mmol} / \mathrm{L}$ fructose (F), $5 \mathrm{mmol} / \mathrm{L}$ glycine $(G)$, or fructose plus glycine $(F+G)$ at 20 minutes prior to and then continuously after reperfusion. Some hepatocytes were incubated in aerobic HDM for 12 hours without exposure to ischemia (normoxia). The percentage of TUNEL positive nuclei after 12 hours of reperfusion was determined, as described in Figure 3 . Results are means $\pm \mathrm{SE}$ from 3 hepatocyte isolation. $* P<0.05$ vs. normoxia.

blocked by anoxia and metabolic inhibition. ${ }^{32,36}$ To examine the effect of glycolytic ATP availability on the development of apoptosis after reperfusion, hepatocytes were treated with fructose or glycine alone at 20 minutes prior to and then continuously after reperfusion. The percentage of apoptosis was then evaluated by TUNEL staining at 12 hours after reperfusion (Figure 5). In the presence of fructose, about $60 \%$ of cells became TUNEL positive. However, when cells were reperfused with glycine alone, only about $20 \%$ of hepatocytes were TUNEL positive. ATP levels were also measured. After 8 hours incubation in reperfusion media without preceding ischemia, ATP was $16.7 \pm 0.2 \mathrm{nmol} / 10^{6}$ cells (Table 1 ). After simulated ischemia and 8 hours of reperfusion, ATP decreased by $98 \%$, a finding that is consistent with earlier data showing virtually complete ATP depletion and cell death within 2 hours of reperfusion. 5 When fructose was present during reperfusion, ATP was partially preserved to $27 \%$ of normoxic levels (Table 1 ). In contrast, after ischemia/reperfusion with glycine alone, ATP was only $7 \%$ of normoxic levels, even though glycine nearly completely prevented necrotic cell death. ATP after reperfusion in the presence of fructose plus glycine together recovered to $36 \%$ of normoxic cells. Thus, although fructose and glycine both prevented necrosis, the 4-5-fold higher ATP levels after reperfusion with fructose with and without glycine appeared to direct cells into apoptosis.

\section{Caspase Inhibitors Do Not Prevent Necrotic Cell Death After Ischemia/Reperfusion}

In additional experiments, we investigated the effects of caspase inhibitors on necrotic death when hepatocytes were reperfused in the absence of fructose plus glycine. In the absence of fructose plus glycine, pancaspase inhibition with zVAD and caspase 3 inhibition with DEVD did not prevent necrotic cell killing after reperfusion, as measured by propidium iodide fluorometry (Figure 6). Therefore, necrotic cell death after ischemia/reperfusion in the absence of fructose plus glycine occurred independently of caspase activation.

\section{Discussion}

Ischemia/reperfusion injury is a complex phenomenon involving cell-to-cell interactions, tissue architecture, and zonal structure, as well as changes in individual cells. $^{37,38}$ Here, we addressed how the MPT leads to necrotic and apoptotic death of cultured rat hepatocytes subjected to simulated ischemia/reperfusion. Anaerobic glycolysis and ATP hydrolysis during ischemia rapidly decreases tissue $\mathrm{pH}$, which protects against hypoxic cell killing in heart, liver, kidney, vascular, and endothelial cells. $^{2-4,39}$ However, the recovery from acidosis to physiologic $\mathrm{pH}$ after reperfusion precipitates necrotic cell killing. ${ }^{1-5}$ Previously, our laboratory showed that onset of the MPT and subsequent ATP depletion are causative events in $\mathrm{pH}$-dependent necrosis to reperfused hepatocytes. ${ }^{5}$ In $\mathrm{pH}$-dependent reperfusion injury, CsA pre-

Table 1. ATP Concentrations in Hepatocytes Reperfused in the Presence or Absence of Fructose and Glycine

\begin{tabular}{lcccc}
\hline & ATP $\left(\mathrm{nmol} / 10^{6}\right.$ cells $)$ & & Glycine & Fructose + Glycine \\
\hline Normoxia & No addition & Fructose & $1.20 \pm 0.31^{a}$ & $6.01 \pm 0.09^{a, b}$ \\
\hline $16.7 \pm 0.21^{a, b}$ & $0.30 \pm 0.08^{b}$ & $4.59 \pm 0.11^{a, b}$ & \\
\hline
\end{tabular}

NOTE. Hepatocytes were exposed for 4 hours of anoxia in anaerobic $\mathrm{KRH}$ at pH 6.2 and then reoxygenated in HDM at pH 7.4 for 8 hours. Some hepatocytes were incubated with $20 \mathrm{mmol} / \mathrm{L}$ fructose, $5 \mathrm{mmol} / \mathrm{L}$ glycine, or fructose plus glycine beginning at 20 minutes before reperfusion and then continuously after reperfusion. Normoxic cells were incubated without exposure to anoxia. "No addition" cells were exposed to ischemia/ reperfusion without fructose or glycine. ATP was measured as described in Materials and Methods section. Values are means \pm SE from 3 hepatocyte isolations.

ap $<0.001$ vs. No addition.

${ }^{b P}<0.05$ vs. glycine. 


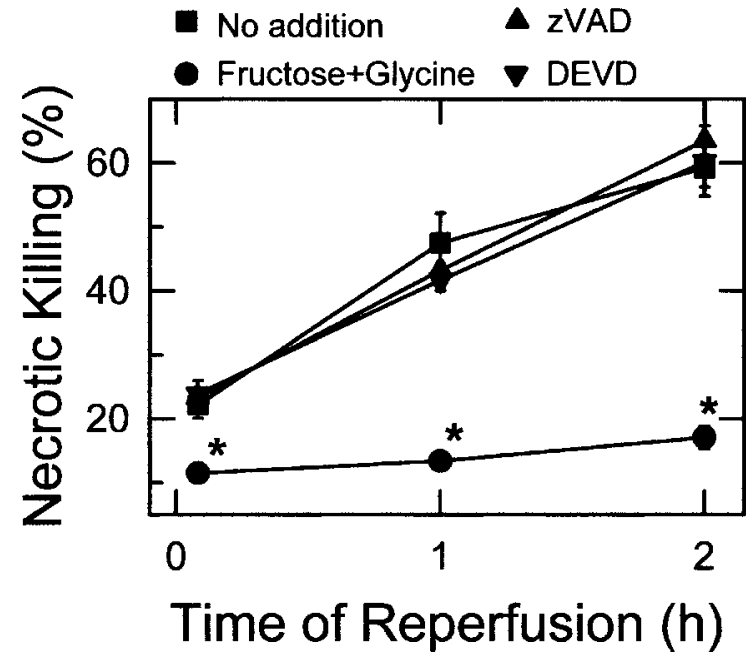

Figure 6. Lack of inhibition of reperfusion-induced necrotic cell death by pancaspase and caspase 3 inhibitors. Hepatocytes were exposed to simulated ischemia/reperfusion as described in Figure 1 in the presence of $20 \mathrm{mmol} / \mathrm{L}$ fructose plus $5 \mathrm{mmol} / \mathrm{L}$ glycine, $50 \mu \mathrm{mol} / \mathrm{L}$ zVAD, $50 \mu \mathrm{mol} / \mathrm{L}$ DEVD, or no addition, beginning at 20 minutes before and then continuously after reperfusion. Cell viability was assessed by propidium iodide fluorometry. Results are means $\pm \mathrm{SE}$ from 4 hepatocyte isolations. $* P<0.05$ vs. other groups.

vents MPT-induced mitochondrial depolarization, inner membrane permeabilization, and ATP exhaustion after reperfusion and blocks the necrotic cell killing that ensues. Here, we show that fructose prevented this necrotic cell death by supplying ATP via glycolysis (Figure 2 and Table 1), consistent with the previous work, showing that preservation of $15 \%$ to $20 \%$ of normal ATP is sufficient to prevent necrotic cell killing in models of hypoxia/ischemia. ${ }^{32,36}$ Glycine also prevents MPT-dependent reperfusion injury but protects after ATP depletion by preventing plasma membrane failure. $^{5,31,40-42}$ Cytoprotection by fructose and glycine is downstream of the MPT because neither fructose nor glycine block mitochondrial depolarization and inner membrane permeabilization induced in situ by reperfusion or an MPT-inducing calcium ionophore. ${ }^{5,43}$ In addition to causing necrotic cell death, ischemia/reperfusion injury can also lead to apoptosis in liver and other organs. ${ }^{14-16}$ Because the MPT is also implicated in apoptotic cell death, we investigated whether $\mathrm{pH}$-dependent onset of the MPT after reperfusion would also initiate apoptosis.

After exposure of cultured rat hepatocytes to anoxia at $\mathrm{pH} 6.2$ (simulated ischemia), necrotic cell death occurred even after reoxygenation with a complete culture media (Figure 1), confirming earlier results after reperfusion in KRH. ${ }^{5}$ Fructose plus glycine treatment during reperfusion prevented this necrotic cell killing (Figure 1). When necrotic cell death was prevented in this way, apoptosis occurred instead, as assessed by nuclear changes (Figure 2), TUNEL labeling (Figure 3), and caspase 3 activation (Figure 4). Apoptosis was caspase- 3 dependent because pancaspase and caspase 3 inhibition, but not caspase 8 inhibition, prevented TUNEL staining (Figure 3). CsA, a specific blocker of the MPT in reperfused hepatocytes, ${ }^{5}$ also prevented apoptosis, whereas tacrolimus, an immunosuppressive agent that does not block the MPT, did not (Figure $3 A$ and $B$ ). Taken together, these findings support the conclusion that the MPT initiates caspasedependent apoptosis after simulated ischemia/reperfusion.

Onset of the MPT leads to mitochondrial swelling, outer membrane rupture, and release of cytochrome $c$ into the cytosol. The interaction of cytochrome $c$ with apoptosis protease activating factor-1 (APAF-1) leads to caspase 9 activation, which then activates caspase 3 . APAF-1- and cytochrome c-dependent activation of caspase 9 requires ATP or the less abundant dATP. ${ }^{30}$ Accordingly, ATP has been proposed to act as a "switch" between apoptosis and necrosis. ${ }^{33-35}$ To investigate the importance of ATP, we reperfused hepatocytes with fructose or glycine alone. Fructose is a glycolytic substrate that promotes ATP formation after reperfusion. ${ }^{32,36}$ Reperfusion with fructose or fructose plus glycine increased ATP (Table 1) and prevented necrotic cell death (Figure 2), but instead promoted apoptotic cell death, as documented by caspase 3 activation (Figure 4) and TUNEL staining, a consequence of caspase 3-dependent activation of endonucleases (Figures 3 and 5). Reperfusion with glycine alone was poorly effective at restoring ATP and did not promote apoptosis, although glycine did prevent necrotic cell death (Table 1 and Figure 1). Glycine is a cytoprotective amino acid that prevents plasma membrane permeabilization, which occurs downstream of ATP depletion. ${ }^{41,42,44}$ Because neither fructose nor glycine prevents the MPT after reperfusion of hepatocytes, these results support the conclusion that ATP is required for development of MPT-dependent apoptosis after ischemia/reperfusion injury to hepatocytes.

The $\mathrm{K}_{\mathrm{M}}$ of ATP for activating apoptosomes (the APAF-1/procaspase 9/cytochrome c complex) is about $0.4 \mathrm{mmol} / \mathrm{L}$ in a cell-free system. ${ }^{45}$ Assuming an intracellular volume of $5.8 \mu \mathrm{L} / 10^{6}$ hepatocytes, ${ }^{46}$ intracellular ATP concentration after reperfusion with glycine alone was about $0.2 \mathrm{mmol} / \mathrm{L}$, whereas ATP concentration after reperfusion with fructose alone or fructose plus glycine together was 0.8 to $1 \mathrm{mmol} / \mathrm{L}$. Thus, ATP concentration would appear to be limiting for apoptosome-mediated caspase activation after reperfusion with glycine alone but not after reperfusion with fructose alone or fructose 
plus glycine together, which is consistent with the relative extent of caspase-dependent TUNEL staining after reperfusion under the 3 reperfusion conditions.

These results after simulated ischemia/reperfusion are also consistent with earlier findings examining toxic injury to hepatocytes by the calcium ionophore $\mathrm{Br}$ A23187.43 Br-A23187 initiated onset of the MPT, which in turn caused either necrosis or apoptosis, depending on the availability of glycolytic ATP. Fructose rescued hepatocytes from $\mathrm{Br}$-A23187-induced necrotic cell death but did not prevent onset of the MPT. Instead, hepatocytes developed apoptosis after 10 hours of fructose treatment, and this apoptosis was blocked by CsA. Subsequent progression into necrosis or apoptosis after reperfusion then depended on whether an alternate source of glycolytic ATP was available to compensate for the depletion of ATP after onset of the MPT.

A previous study indicated that ATP depletion by fructose inhibited TNF- $\alpha$-induced killing of hepatocytes, ${ }^{47}$ which seems contrary to our observation that fructose promotes apoptosis after ischemia/reperfusion. Resolving this inconsistency between the 2 models will have to be the goal of future work. However, effects of fructose other than ATP depletion may be responsible for its antiapoptotic effect after TNF- $\alpha$ treatment. Specifically, fructose addition to aerobic cells causes a profound decrease of inorganic phosphate $(\mathrm{Pi})$ in liver tissue as sugar phosphates are formed by the action of fructokinase and subsequent steps in glycolysis. $\mathrm{Pi}$ is a well known factor promoting the MPT, ${ }^{48,49}$ and a decline of Pi and the consequent suppression of the MPT by fructose treatment may be the reason that fructose retards TNF- $\alpha-$ induced apoptosis. Indeed, $\mathrm{Pi}$ treatment with fructose restores TNF- $\alpha$-induced apoptosis. ${ }^{47}$ In addition, we reported previously that fructose delays (but does not prevent) onset of the MPT after exposure of hepatocytes to calcium ionophore, which may be related to fructoseinduced Pi depletion. ${ }^{43}$ Moreover, in the present work, we found that ATP at $27 \%$ to $36 \%$ of normal levels is still sufficient to support apoptosis.

In conclusion, the balance between ATP depletion after the MPT and ATP generation by glycolysis operates a switch determining whether the fate of the cell will be necrosis or apoptosis after simulated ischemia/reperfusion-induced onset of the MPT (Figure 7). When ATP loss is profound, necrotic cell death rapidly occurs because of glycine sensitive breakdown of the plasma membrane permeability barrier. When ATP loss after the MPT is rescued by glycolysis, apoptosis develops instead, mediated by cytochrome c release and ATP-dependent caspase 3 activation. Nonetheless, secondary necrotic cell

\section{Ischemia/reperfusion}

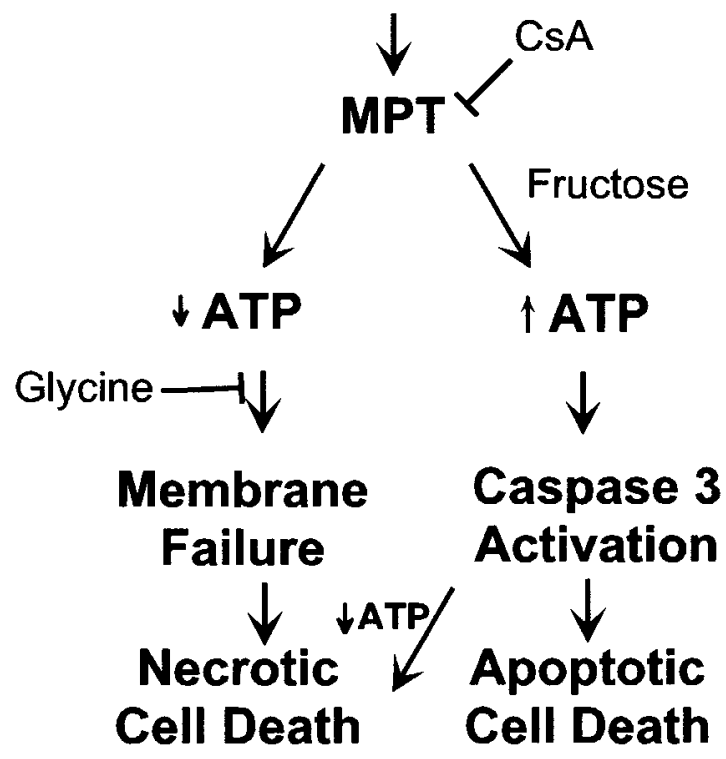

Figure 7. Scheme of MPT-dependent necrotic and apoptotic cell death after ischemia/reperfusion. See text for details.

death may ensue after apoptosis is initiated if ATP subsequently becomes depleted. In this model, one mechanism, the MPT, leads to either apoptosis or necrosis. Our findings in support of the model are consistent with the well-documented need for ATP to execute apoptosis and the roles of mitochondrial respiratory dysfunction and ATP depletion in necrotic cell death. ${ }^{33-35}$ Controversy has recently arisen as to whether cell killing after ischemia/reperfusion to liver is apoptosis or necrosis. ${ }^{23,25}$ In these discussions, it is implicitly assumed that apoptotic and necrotic cell death are distinctly different entities. Our findings show that this assumption may not be valid and that pathways leading to necrosis and apoptosis can be shared, a phenomenon we have named "necrapoptosis." 50 In necrapoptosis, common pathways, such as the MPT, initiate events that culminate in either apoptosis or necrosis, depending on other variables, such as ATP supply. Thus, ischemia/reperfusion through common mechanisms causes both apoptosis and necrosis.

\section{References}

1. Bond JM, Herman B, Lemasters JJ. Protection by acidotic $\mathrm{pH}$ against anoxia/reoxygenation injury to rat neonatal cardiac myocytes. Biochem Biophys Res Commun 1991;179:798-803.

2. Currin RT, Gores GJ, Thurman RG, Lemasters JJ. Protection by acidotic $\mathrm{pH}$ against anoxic cell killing in perfused rat liver: evidence for a pH paradox. FASEB J 1991;5:207-210.

3. Bond JM, Chacon E, Herman B, Lemasters JJ. Intracellular pH and $\mathrm{Ca}^{2+}$ homeostasis in the $\mathrm{pH}$ paradox of reperfusion injury to neonatal rat cardiac myocytes. Am J Physiol 1993;265:C129C137.

4. Zager RA, Schimpf BA, Gmur DJ. Physiological pH. Effects on posthypoxic proximal tubular injury. Circ Res 1993;72:837-846. 
5. Qian T, Nieminen AL, Herman B, Lemasters JJ. Mitochondrial permeability transition in $\mathrm{pH}$-dependent reperfusion injury to rat hepatocytes. Am J Physiol 1997;273:C1783-C1792.

6. Griffiths EJ, Halestrap AP. Protection by Cyclosporin A of ischemia/reperfusion-induced damage in isolated rat hearts. $J \mathrm{Mol}$ Cell Cardiol 1993;25:1461-1469.

7. Trump BF, Berezesky IK, Chang SH, Phelps PC. The pathways of cell death: oncosis, apoptosis, and necrosis. Toxicol Pathol 1997;25:82-88.

8. Bellamy CO, Malcomson RD, Harrison DJ, Wyllie AH. Cell death in health and disease: the biology and regulation of apoptosis. Semin Cancer Biol 1995;6:3-16.

9. Kaufmann SH, Hengartner MO. Programmed cell death: alive and well in the new millennium. Trends Cell Biol 2001;11:526-534.

10. Gupta S. Molecular steps of death receptor and mitochondrial pathways of apoptosis. Life Sci 2001;69:2957-2964.

11. Bradham CA, Qian T, Streetz K, Trautwein C, Brenner DA, Lemasters $\mathrm{JJ}$. The mitochondrial permeability transition is required for tumor necrosis factor alpha-mediated apoptosis and cytochrome c release. Mol Cell Biol 1998;18:6353-6364.

12. Hatano E, Bradham CA, Stark A, limuro Y, Lemasters JJ, Brenner DA. The mitochondrial permeability transition augments Fas-induced apoptosis in mouse hepatocytes. J Biol Chem 2000;275: 11814-11823.

13. Trump BF, Goldblatt PJ, Stowell RE. Studies of necrosis in vitro of mouse hepatic parenchymal cells. Ultrastructural alterations in endoplasmic reticulum, Golgi apparatus, plasma membrane, and lipid droplets. Lab Invest 1965;14:2000-2028.

14. Schumer M, Colombel MC, Sawczuk IS, Gobe G, Connor J, O'Toole KM, Olsson CA, Wise GJ, Buttyan R. Morphologic, biochemical, and molecular evidence of apoptosis during the reperfusion phase after brief periods of renal ischemia. Am J Pathol 1992;140:831-838.

15. Gottlieb RA, Burleson KO, Kloner RA, Babior BM, Engler RL. Reperfusion injury induces apoptosis in rabbit cardiomyocytes. J Clin Invest 1994;94:1621-1628.

16. Gao W, Bentley RC, Madden JF, Clavien PA. Apoptosis of sinusoidal endothelial cells is a critical mechanism of preservation injury in rat liver transplantation. Hepatology 1998;27:16521660.

17. Lemasters JJ, Bunzendahl H, Thurman RG, Preservation of the liver. In: Maddrey WC, Schiff ER, Sorrell MF, eds. Transplantation of the liver. 3rd ed. Philadelphia: Lippincott Williams \& Wilkins, 2001:251-273.

18. Nieminen AL, Gores GJ, Bond JM, Imberti R, Herman B, Lemasters JJ. A novel cytotoxicity screening assay using a multiwell fluorescence scanner. Toxicol Appl Pharmacol 1992;115:147155.

19. Nieminen AL, Gores GJ, Wray BE, Tanaka Y, Herman B, Lemasters JJ. Calcium dependence of bleb formation and cell death in hepatocytes. Cell Calcium 1988;9:237-246.

20. Gores GJ, Nieminen AL, Fleishman KE, Dawson TL, Herman B, Lemasters JJ. Extracellular acidosis delays onset of cell death in ATP-depleted hepatocytes. Am J Physiol 1988;255:C315-C322.

21. Gressner AM, Polzar B, Lahme B, Mannherz HG. Induction of rat liver parenchymal cell apoptosis by hepatic myofibroblasts via transforming growth factor $\beta$. Hepatology 1996;23:571-581.

22. Shah KA, Shurey S, Green CJ. Apoptosis after intestinal ischemia-reperfusion injury: a morphological study. Transplantation 1997;64:1393-1397.

23. Natori S, Selzner M, Valentino KL, Fritz LC, Srinivasan A, Clavien PA, Gores GJ. Apoptosis of sinusoidal endothelial cells occurs during liver preservation injury by a caspase-dependent mechanism. Transplantation 1999;68:89-96.

24. Scarabelli T, Stephanou A, Rayment N, Pasini E, Comini L, Curello S. Apoptosis of endothelial cells precedes myocyte cell apopto- sis in ischemia/reperfusion injury. Circulation 2001;104:253256.

25. Gujral JS, Bucci TJ, Farhood A, Jaeschke H. Mechanism of cell death during warm hepatic ischemia-reperfusion in rats: apoptosis or necrosis? Hepatology 2001;33:397-405.

26. Fournier N, Ducet G, Crevat A. Action of cyclosporine on mitochondrial calcium fluxes. J Bioenerg Biomembr 1987;19:297303.

27. Crompton $\mathrm{M}$, Ellinger $\mathrm{H}$, Costi $\mathrm{A}$. Inhibition by cyclosporin $\mathrm{A}$ of a $\mathrm{Ca}^{2+}$-dependent pore in heart mitochondria activated by inorganic phosphate and oxidative stress. Biochem J 1988;255: 357-360.

28. Ho S, Clipstone N, Timmermann L, Northrop J, Graef I, Fiorentino D, Nourse J, Crabtree GR. The mechanism of action of cyclosporin A and FK506. Clin Immunol Immunopathol 1996;80:S40S45.

29. Griffiths EJ, Halestrap AP. Further evidence that cyclosporin A protects mitochondria from calcium overload by inhibiting a matrix peptidyl-prolyl cis-trans isomerase. Implications for the immunosuppressive and toxic effects of cyclosporin. Biochem J 1991; 274:611-614.

30. Liu X, Kim CN, Yang J, Jemmerson R, Wang X. Induction of apoptotic program in cell-free extracts: requirement for dATP and cytochrome c. Cell 1996;86:147-157.

31. Nieminen AL, Dawson TL, Gores GJ, Kawanishi T, Herman B, Lemasters JJ. Protection by acidotic $\mathrm{pH}$ and fructose against lethal injury to rat hepatocytes from mitochondrial inhibitors, ionophores and oxidant chemicals. Biochem Biophys Res Commun 1990;167:600-606.

32. Nieminen AL, Saylor AK, Herman B, Lemasters JJ. ATP depletion rather than mitochondrial depolarization mediates hepatocyte killing after metabolic inhibition. Am J Physiol 1994;267:C67C74.

33. Richter C, Schweizer M, Cossarizza A, Franceschi C. Control of apoptosis by the cellular ATP level. FEBS Lett 1996;378:107110.

34. Leist M, Single B, Castoldi AF, Kuhnle S, Nicotera P. Intracellular adenosine triphosphate (ATP) concentration: a switch in the decision between apoptosis and necrosis. J Exp Med 1997;185: 1481-1486.

35. Eguchi Y, Shimizu S, Tsujimoto Y. Intracellular ATP levels determine cell death fate by apoptosis or necrosis. Cancer Res 1997; 57:1835-1840.

36. Anundi I, King J, Owen DA, Schneider H, Lemasters JJ, Thurman RG. Fructose prevents hypoxic cell death in liver. Am J Physiol 1987;253:G390-G396.

37. Lemasters JJ. Hypoxic, ischemic and reperfusion injury to liver. In: Arias IM, Boyer JL, Fausto N, Jakoby WB, Schachter D, Shafritz DA, eds. The liver. Biology and pathobiology. 4th ed. New York: Raven, 2001:257-279.

38. Jaeschke H, Gores GJ, Cederbaum AI, Hinson JA, Pessayre D, Lemasters JJ. Mechanisms of hepatotoxicity. Toxicol Sci 2002; 65:166-176.

39. Nishimura Y, Romer LH, Lemasters JJ. Mitochondrial dysfunction and cytoskeletal disruption during chemical hypoxia to cultured rat hepatic sinusoidal endothelial cells: the $\mathrm{pH}$ paradox and cytoprotection by glucose, acidotic $\mathrm{pH}$, and glycine. Hepatology 1998;27:1039-1049.

40. Weinberg JM. The cell biology of ischemic renal injury. Kidney Int 1991;39:476-500.

41. Dong Z, Patel Y, Saikumar P, Weinberg JM, Venkatachalam MA. Development of porous defects in plasma membranes of adenosine triphosphate-depleted Madin-Darby canine kidney cells and its inhibition by glycine. Lab Invest 1998;78:657-668.

42. Nishimura Y, Lemasters JJ. Glycine blocks opening of a death channel in cultured hepatic sinusoidal endothelial cells during chemical hypoxia. Cell Death Differ 2001;8:850-858. 
43. Qian T, Herman B, Lemasters JJ. The mitochondrial permeability transition mediates both necrotic and apoptotic death of hepatocytes exposed to Br-A23187. Toxicol Appl Pharmacol 1999; 154:117-125.

44. Saikumar P, Dong Z, Weinberg JM, Venkatachalam MA. Mechanisms of cell death in hypoxia/reoxygenation injury. Oncogene 1998;17:3341-3349.

45. Genini D, Budihardjo I, Plunkett W, Wang X, Carrera CJ, Cottam HB, Carson DA, Leoni LM. Nucleotide requirements for the in vitro activation of the apoptosis protein-activating factor-1-mediated caspase pathway. J Biol Chem 2000;275:29-34.

46. Gores GJ, Flarsheim CE, Dawson TL, Nieminen AL, Herman B, Lemasters JJ. Swelling, reductive stress, and cell death during chemical hypoxia in hepatocytes. Am J Physiol 1989;257:C347C354.

47. Latta M, Kûnstle G, Leist M, Wendel A. Metabolic depletion of ATP by fructose inversely controls CD95-and tumor necrosis factor receptor 1-mediated hepatic apoptosis. J Exp Med 2000;191: 1975-1985.
48. Gunter TE, Pfeiffer DR. Mechanisms by which mitochondria transport calcium. Am J Physiol 1990;258:C755-C786.

49. Zoratti M, Szabo I. The mitochondrial permeability transition. Biochim Biophys Acta 1995;1241:139-176.

50. Lemasters JJ V. Necrapoptosis and the mitochondrial permeability transition: shared pathways to necrosis and apoptosis. Am J Physiol 1999;276:G1-G6.

Received February 26, 2002. Accepted October 31, 2002.

Address requests for reprints to: John J. Lemasters, M.D., Ph.D., Department of Cell and Developmental Biology, University of North Carolina at Chapel Hill, Campus Box 7090, 236 Taylor Hall, Chapel Hill, North Carolina 27599-7090. e-mail: lemaster@med.unc.edu; fax: (919) 966-7197.

Supported in part by grants 1 P01 DK59340 and 5-R01 AG07218 from the National Institutes of Health and imaging facilities by NIH Center grants 5-P30-DK34987 and 1-P50-AA11605. 